\title{
Variations of the North and South Pacific Subtropical Gyres over the past 400 kyrs
}

\author{
K. FURUKAWA ${ }^{1}$, O. SEKI ${ }^{2}$ \\ ${ }^{1}$ Hokkaido University, Hokkaido 060-0819 Japan \\ (k.furukawa@pop.lowtem.hokudai.ac.jp) \\ ${ }^{2}$ Hokkaido University, Hokkaido 060-0819 Japan \\ (seki@pop.lowtem.hokudai.ac.jp)
}

The gyre in the ocean is thought to play an important role in the climate system as meridional heat and material transports between low and high latitudes. In late Pleistocene paleoceanographic study, previous study revealed that the large variation of intensity of North Pacific Subtropical Gyre (NPSG) associated with glacial-interglacial cycles with 23 kyr cycle (Yamamoto et al., 2008), suggesting a precession control on intensity of NPSG circulation. However, the mechanism driving the long-term variability of the subtropical gyre and its role in global climate change are still remains uncertain.

In this study, we reconstructed and analyze mid sea surface temperature (SST) records in the western and eastern sides in the NPSG and South Pacific Subtropical Gyre (SPSG) for the past $400 \mathrm{kyrs}$ to investigate evolution of those gyres. We reconstructed intensity of the gyre circulation from $\Delta \mathrm{SST}$ difference between west and eastern sides of the gyres. The west-east $\Delta \mathrm{SST}$ record in SPSG show orbital scale variations over the past 400 kyrs. Spectral analysis suggests predominance of 23 and $41 \mathrm{kyr}$ cycles, suggesting precession and obliquity control on SPSG. 